\title{
A gathering of the dying
}

\author{
Paul Malik MD FRCPC
}

$\mathrm{I}$ n our corporeal existence, all events occur at a time and place. From a clinical context, time measures are given the priority. Time before presentation of symptom onset, or door-to-needle or -balloon times are key factors influencing outcomes for acute ST segment elevation myocardial infarction. Perhaps our understanding of disease would be buttressed by also considering 'place'. Geographical location of patients may reveal disease clusters. These data would be useful for everything from health resource allocation - placing cardiac rehabilitation clinics near those locations, for example - to planning the most efficient ambulance route for transfer to a tertiary care centre. This interaction of environment or place with health is known as medical geography. The ecology of human health and disease has also been studied under different banners: geographical pathology, medical topography, geographical epidemiology and geomedicine.

The importance of location has been recognized for more than 2000 years:

On airs, waters, and places

Whoever wishes to investigate medicine properly, should proceed thus: in the first place to consider the seasons of the year, and what effects each of them produces (for they are not at all alike, but differ much from themselves in regard to their changes). Then the winds, the hot and cold, especially as are common to all countries, and then such as are peculiar to each locality. We must also consider the qualities of the waters, for as they differ from one another in taste and weight, so also do they differ much in their qualities. In the same manner, when one comes into a city to which he is a stranger, he ought to consider its situation, how it lies as to the winds and the rising of the sun; for its influence is not the same whether it lies to the north or the south, to the rising or setting sun. These things one ought to consider most attentively and concerning the waters which the inhabitants use, whether they be marshy and soft, or hard and running from elevated and rocky situations, and then if saltish and unfit for cooking; and the ground, whether it be naked and deficient in water, or wooded and well watered, and whether it lies in a hollow, confined situation, or is elevated and cold; and the mode in which the inhabitants live, and what are their pursuits, whether they are fond of drinking and eating to excess and given to indolence, or are fond of exercise and labor, and not given to excess in eating and drinking.

From these things he must proceed to investigate everything else.

Hippocrates (circa 400 BC)

Indeed, this is a remarkably prescient statement, considering it was espoused more than two millenia before germ theory! From Hippocrates' eloquence, we begin to see the complexities of 'place'. The idea of place is not as simple as a point on the map or even direct environmental factors; it includes cultural influence, socioeconomic status, availability of health care resources, genetic factors and population migration, to name only a few. As daunting as the study of place seems, medical geographers have made important contributions.

The most famous example is the work of Dr John Snow during a cholera epidemic in London in 1854. This was during a time that people believed disease to originate from miasmas or vapours. Snow plotted maps of the homes of cholera victims, along with the locations of water pumps. He found one pump central to all the victims. After he instructed the authorities to remove the handle of the pump and render it unusable, the number of new cholera cases declined dramatically. Again, this was a remarkable achievement, considering that the cholera vibrio was not isolated until 1883 by Robert Koch.

A more contemporary example is the NASA Earth Observatory program to combat malaria in developing countries. Malaria is one of the most important problems facing the international community. The disease creates a vicious circle, because it is more prevalent in impoverished nations who can ill afford to deal with its consequences. The disease, in turn, hinders economic development to perpetuate the cycle and guarantee its existence. The cost to the developing world in lost productivity is more than $\$ 2$ billion per year. The problem stems not from poor hygiene, water supply or diet, but rather a lack of defence against the Anopheles mosquito. Cost constraints do not make widespread spraying of insecticides a viable option. It has been learned, however, that certain species of the Anopheles mosquito breed in water with blue-green algae. Satellite imagery can identify water rich in blue-green algae, because it emits a characteristic wavelength of energy. This creates a surgical strike map in which insecticide spraying can be done to achieve maximum results. Alternatively, researchers have learned that $50 \%$ of malaria cases originate from $15 \%$ of the houses in villages. Targeting these houses for infection control promises to stem the spread of disease.

Medical geography clearly lends itself to the study of vector-borne or communicable disease, particularly in the developing world. At first glance, it seems to be irrelevant in more affluent nations, particularly as it applies to what are considered lifestyle diseases, such as atherosclerosis. This may not be the case. It has been appreciated, for example, that high levels of ambient air pollution increase the risk of coronary events and even mortality (1-4). This link to coronary disease is a tantalizing hint of new, uncharted mechanistic frontiers to be researched in our understanding of atherosclerotic plaque stability. It is also a social polemic couched in the language of science that reminds us of the dire need to heed the words of Nobel laureates such as Al Gore and others.

Medical geography is a rigorous scientific discipline that requires training in medicine and advanced statistical skills. Professional medical geographers are few and far between. While this threatens the advancement of the field, the vacuum represents an opportunity for amateur medical geographers to make important contributions to local delivery of care, much like professional astronomers rely on the observations of amateur ones through their sheer number. Posing the right question and geographical data analysis are skills that can be learned through available online resources. An online textbook of medical geography provides a good introduction to the history and applications of medical geography, including techniques in spatial analysis and studies of disease diffusion. Perhaps the most easily accessible software to map healthrelated data is Google Earth. The program has been exploited for commercial use, but its research potential, particularly as it relates to health care, remains largely untapped. The program is capable of plotting multiple layers of data at multiple scales. This makes it useful for local quality assurance and for more global resource allocation issues.

Medical geography adds an extra dimension to the study of disease. It may also be a way to link multiple disparate databases by virtue of a common element. The tools for local application are available freely. The most practical applications, however, will come from projects initiated by health care professionals, because they are aware of the local challenges to optimal patient care, including those of access and quality. 


\section{Selected sites}

1. National Cancer Institute. Cancer Mortality Maps \& Graphs. $<$ www3.cancer.gov/atlasplus/type.html >

2. City University, London, United Kingdom. <vega.soi.city.ac.uk/ dk708/pg1_1.htm>

3. Wikipedia. Health geography. <en.wikipedia.org/wiki/Health_geography>

4. NASA - Earth Observatory. Mapping malaria. <eobglossary.gsfc.nasa.gov/Study/Malaria/printall.php>

\section{REFERENCES}

1. Dockery DW, Pope CA III, Xu X, et al. An association between air pollution and mortality in six U.S. cities. N Engl J Med 1993;329:1753-9

2. Pope CA III, Thun MJ, Namboodiri MM, et al. Particulate air pollution as a predictor of mortality in a prospective study of U.S. adults. Am J Respir Crit Care Med 1995;151:669-74.
5. Online Text - Medical geography.

$<$ books.google.ca/books?id=PCBWr5UySs8C\&pg=PP1\&dq= medical+geography>

6. Google Earth. <earth.google.com>

7. Google Earth Lessons.

<gelessons.com/lessons>
3. Miller KA, Siscovick DS, Sheppard L, et al. Long-term exposure to air pollution and incidence of cardiovascular events in women. N Engl J Med 2007;356:447-58.

4. Peters A, Dockery DW, Muller JE, Mittleman MA. Increased particulate air pollution and the triggering of myocardial infarction. Circulation 2001;103:2810-5.

\section{DR ROBERT E BEAMISH AWARD}

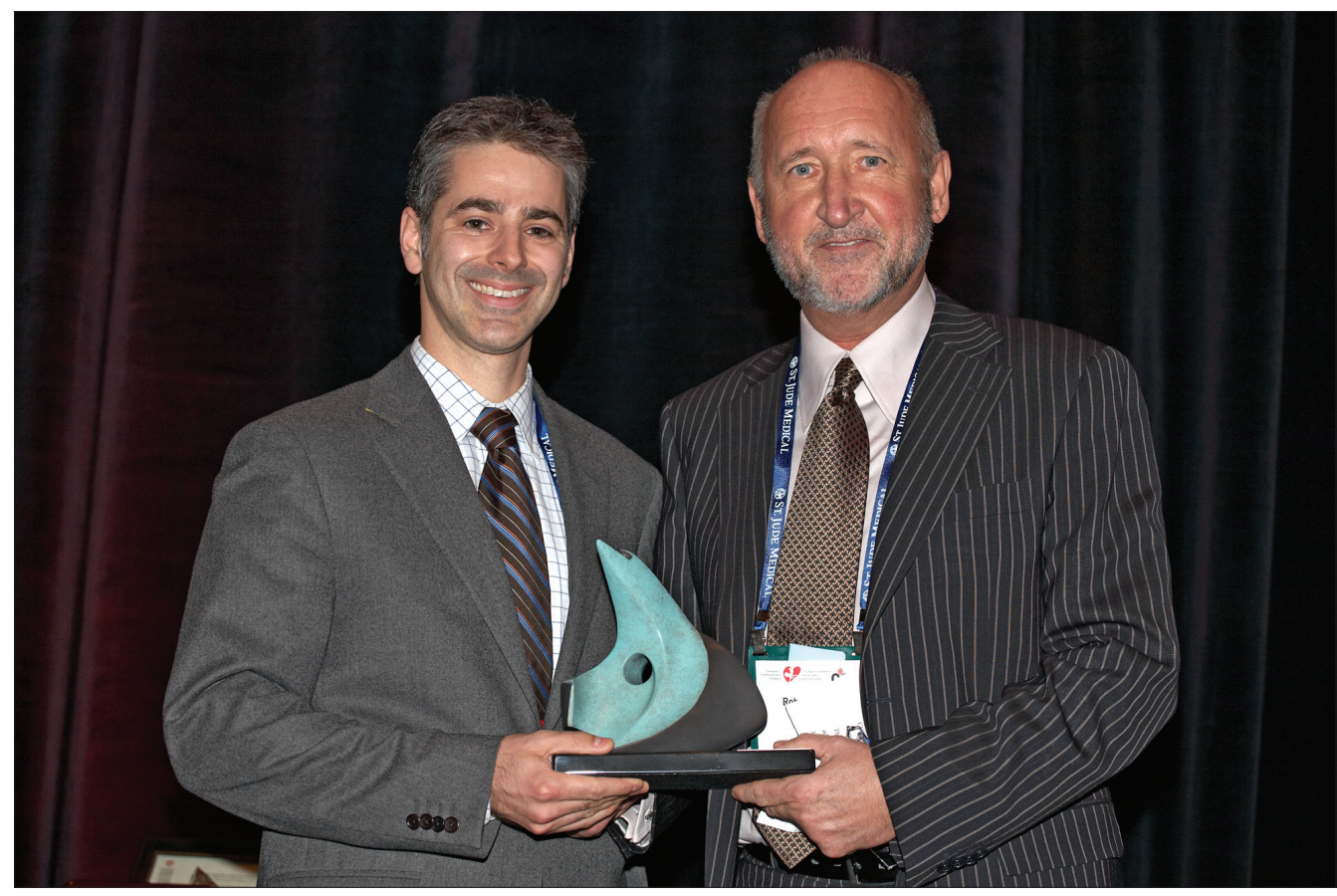

$\mathrm{T}$ The 2007 winner of the Dr Robert E Beamish Award was announced by Robert Kalina, Publisher of The Canadian Journal of Cardiology, at the recent Canadian Cardiovascular Congress in Quebec City, Quebec. Dr Justin A Ezekowitz was recognized for his paper "N-terminal pro-brain natriuretic peptide and the timing, extent and mortality in ST elevation myocardial infarction" (Can J Cardiol 2006;22[5]:393-397).

This award was initiated in 1998 by Pulsus Group in honour of Dr Robert E Beamish, the founding Editor-in-Chief of The Canadian Journal of Cardiology, who served from 1984 to 1996. It is given annually to an individual who made a significant contribution to the field of cardiology, as demonstrated by the impact of original research published in The Canadian Journal of Cardiology and judged by the Editor-in-Chief and Associate Editors. The award consists of $\$ 1,000$ and a Canadian work of art.

Robert Kalina also presented a cheque to the Canadian Cardiovascular Society (CCS). The Canadian Journal of Cardiology is the official journal of the CCS, and each year, Pulsus Group contributes a percentage of revenues derived from the Journal to the Society for use in future research. 